\title{
Investigations of Protonated and Deprotonated Water Clusters Using a Low-Temperature 22-Pole Ion Trap
}

\author{
Y.-S. Wang, C.-H. Tsai, Y. T. Lee, and H.-C. Chang* \\ Institute of Atomic and Molecular Sciences, Academia Sinica, P.O. Box 23-166 Taipei, Taiwan, ROC, and \\ Department of Chemistry, National Taiwan University, Taipei, Taiwan 106, ROC
}

J. C. Jiang

Department of Chemical Engineering, National Taiwan University of Science and Technology, Taipei, Taiwan 106, ROC

\author{
O. Asvany, S. Schlemmer, and D. Gerlich \\ Institute of Physics, Chemnitz University of Technology, 09107 Chemnitz, Germany
}

Received: September 26, 2002; In Final Form: January 7, 2003

\begin{abstract}
A new tandem mass spectrometer, containing a temperature-variable 22-pole ion trap, has been constructed. It is applied, as a first application, to kinetic and spectroscopic investigation of charged water clusters produced from a supersonic expansion. Using low-pressure $\mathrm{He}$ or $\mathrm{H}_{2}$ as buffer gas for collisional thermalization, refrigeration of the ion trap allows a good control of the cluster temperature over the range $77-350 \mathrm{~K}$. It provides an accurate means of determining the dissociation energies of both protonated and deprotonated water cluster ions $\left[\mathrm{H}^{+}\left(\mathrm{H}_{2} \mathrm{O}\right)_{n}\right.$ and $\left.\mathrm{OH}^{-}\left(\mathrm{H}_{2} \mathrm{O}\right)_{m}\right]$ by measuring the dissociation rates at various temperatures along with their internal energies calculated from vibrational frequencies provided by density functional theory calculations. In this report, results of the thermochemical measurements for $\mathrm{H}^{+}\left(\mathrm{H}_{2} \mathrm{O}\right)_{4-10}$ and $\mathrm{OH}^{-}\left(\mathrm{H}_{2} \mathrm{O}\right)_{3-7}$ at well-defined cluster temperatures are presented. The feasibility of using this ion trap to acquire temperaturedependent infrared spectra of charged water clusters is also demonstrated with $\mathrm{H}^{+}\left(\mathrm{H}_{2} \mathrm{O}\right)_{6}$.
\end{abstract}

\section{Introduction}

An important parameter to measure and to control in the study of ion chemistry ${ }^{1}$ and spectroscopy ${ }^{2}$ is the ion temperature. Conventional thermometers, thermocouples for example, provide accurate measurements of the temperature of solid and liquid samples over a wide range. For the temperature determination of high-pressure gas, one can measure the temperature of their sample vessel because collisional motions will fully thermalize the gas with its surroundings. The temperature of gas-phase ions in a high vacuum system is more difficult to measure (and to control) because the ions are intentionally isolated from the vacuum chambers to avoid charge transfer. As a result, the temperature of gas-phase ions is often far above $300 \mathrm{~K}$ owing to the heating effect during ionization, which can create unwanted reactions as well as spectral complications. Several techniques have thus been developed for the reason of temperature control, mainly to lower the temperature of the intentionally isolated ions, such as adiabatic expansion, ${ }^{3}$ evaporative cooling, ${ }^{4}$ sympathetic cooling, ${ }^{5}$ laser cooling, ${ }^{6}$ and cooling by collisions with cold buffer gas. ${ }^{7}$

The collisional cooling method, as to be discussed in this report, is one of the most universal ways for the temperature control (particularly for the internal degrees of freedom) of gasphase ions. In a storage cell, the buffer gas fills more or less the entire region at a well defined temperature and pressure, producing a thermal "bath". Ions in the storage cell are confined

* To whom correspondence should be addressed. translationally by a time-varying electric field and thermalize both internally and kinetically with the bath by collisions. Temperature control of the storage cell can therefore be performed to change the ion temperature. In the 1980s, Gerlich and co-workers ${ }^{8-10}$ developed multipole radio frequency (RF) ion traps, which serve as ion storage cells and can easily be combined with lasers. ${ }^{8}$ Integration of the trap to a refrigeration system enables active temperature control of the storage cell, thereby allowing studies of the temperature dependence of ionmolecule interactions ${ }^{9}$ as well as the thermodynamic and kinetic properties of gas-phase ions and cluster ions. ${ }^{10}$

In this paper, a temperature-variable 22-pole ion trap integrated into a tandem mass spectrometer is used for investigation of charged water clusters, in both protonated $\left[\mathrm{H}^{+}\left(\mathrm{H}_{2} \mathrm{O}\right)_{n}\right]$ and deprotonated $\left[\mathrm{OH}^{-}\left(\mathrm{H}_{2} \mathrm{O}\right)_{m}\right]$ forms, produced from a supersonic expansion. These cluster ions are chosen because water is not only of general interest in physical chemistry but also plays important roles in interstellar space ${ }^{11}$ and in the atmosphere. ${ }^{12}$ The importance of the latter surely stems from the high abundance of water on earth and the ease of charge separation of the water molecule within clusters, ${ }^{13}$ as $\mathrm{H}_{2} \mathrm{O}$ has a high proton affinity of $165 \mathrm{kcal} \mathrm{mol}^{-1}$ and basicity of $157 \mathrm{kcal} \mathrm{mol}^{-1}$ in the gas phase. ${ }^{14}$

Experiments with the water cluster ions $\left[\mathrm{H}^{+}\left(\mathrm{H}_{2} \mathrm{O}\right)_{n}\right]$ go back to the 1970 s when the Kebarle group ${ }^{15}$ first investigated these ions in a pulsed high-pressure mass spectrometer and deduced the cluster bond energies and other thermochemical quantities from the temperature dependence of equilibrium constants. After 


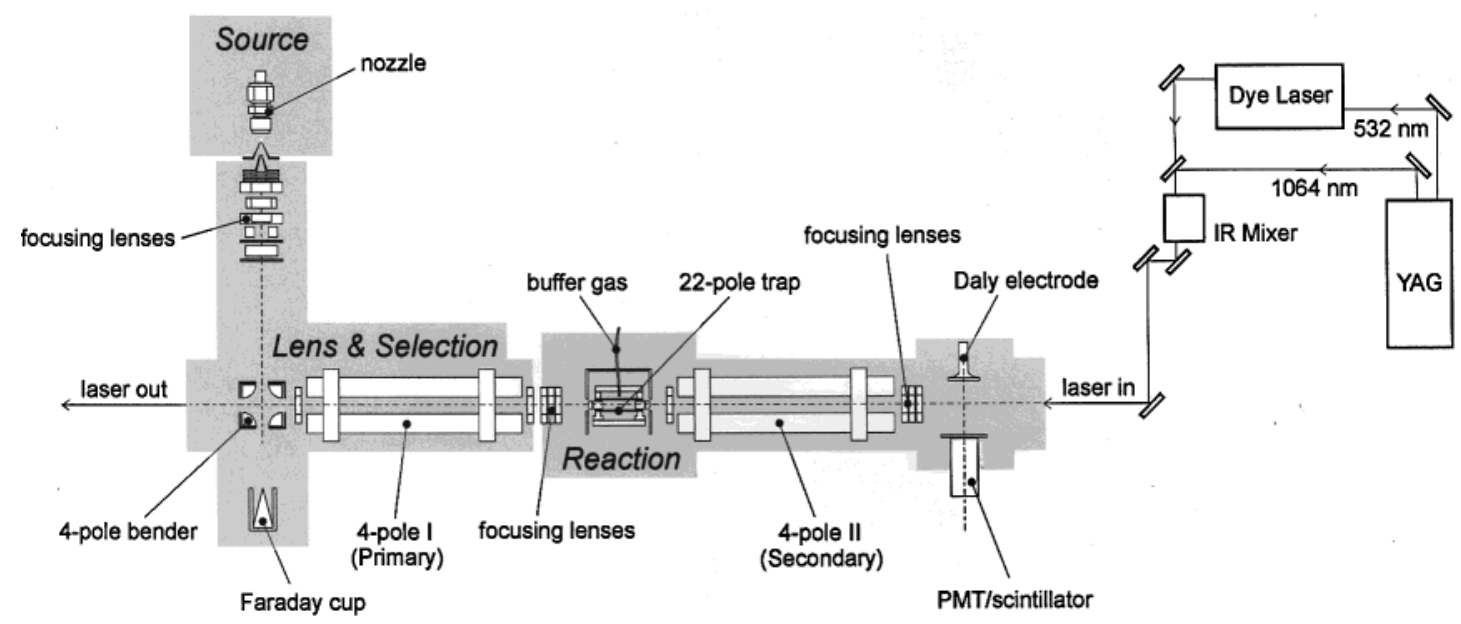

Figure 1. Experimental layout of the temperature-variable 22-pole ion trap mass spectrometer. Shown on the right is the pulsed infrared laser system.

emergence of the corona discharge source $^{3}$ for production of internally cold clusters, detailed spectroscopic investigations followed, ${ }^{16-18}$ revealing important structural information for cluster ions of a size up to $n=8$. Productions as well as spectral assignments of larger clusters become much more difficult because of the complex manifold of structural isomers. Of special interest in the measurements of Kebarle ${ }^{15}$ and other groups ${ }^{19-22}$ is the deviation of the cluster bond energy from a smooth sequence, an indication for the existence of stable structures involving shell closures. The first shell closure was found to occur at $n=4$ for $\mathrm{H}^{+}\left(\mathrm{H}_{2} \mathrm{O}\right)_{n},{ }^{15,19}$ and the special stability of this cluster ion has since been observed in a number of experiments, including the vibrational predissociation spectroscopic measurements of Yeh et al. ${ }^{16}$

In addition to the aforementioned bond energy measurements, the temperature-variable 22-pole ion trap also opens new possibilities to obtain temperature-dependent infrared spectra, from which the population of various isomers as a function of temperature can be inferred. For the cluster ions of interest in this work, there exist many structurally as well as energetically similar isomers, and these isomers are separated by barriers with heights comparable to the strength (a few kcal mol ${ }^{-1}$ ) of the hydrogen bonds that link the water molecules together. Therefore, up to a certain temperature, structural isomerization can occur. Accompanied with this isomerization, the intracluster proton may migrate (through tunneling) and it can either localize at a site close to one water molecule, forming an $\mathrm{H}_{3} \mathrm{O}^{+}\left(\right.$or $\left.\mathrm{OH}^{-}\right)$ ion core, or delocalize between two water molecules, forming an $\mathrm{H}_{5} \mathrm{O}_{2}{ }^{+}$(or $\mathrm{H}_{3} \mathrm{O}_{2}{ }^{-}$) ion core. ${ }^{18,23,24}$ By monitoring the evolution of the spectral changes with temperature, one may investigate the intracluster proton-transfer process closely.

Theoretical analysis for the structural transformation of $\mathrm{H}^{+}\left(\mathrm{H}_{2} \mathrm{O}\right)_{n}$ (refs 25 and 26) and $\mathrm{OH}^{-}\left(\mathrm{H}_{2} \mathrm{O}\right)_{m}$ (refs 27 and 28) has been carried out at various levels of computation. Singer et al., ${ }^{26}$ for example, employed basin-hopping Monte Carlo simulations, examined the topology of $\mathrm{H}^{+}\left(\mathrm{H}_{2} \mathrm{O}\right)_{8}$ as a function of temperature, and concluded that the tree-like topology with chains of $\mathrm{H}_{2} \mathrm{O}$ molecules emanating from a $\mathrm{H}_{3} \mathrm{O}^{+}$core is favored by Gibbs free energies at room temperature. The conclusion is in accord with the spectroscopic observations of Jiang et al. ${ }^{18}$ for $\mathrm{H}^{+}\left(\mathrm{H}_{2} \mathrm{O}\right)_{5-8}$ produced in a molecular beam. However, in the beam experiment, the workable cluster temperature range is very limited, only about $140-200 \mathrm{~K}$, disallowing a test of the simulations. The temperature-variable 22-pole ion trap clearly offers an excellent opportunity to study the isomeric transitions under equilibrium conditions over a much wider temperature range, potentially from 4 to $400 \mathrm{~K}$. Furthermore, the possibility of collision-induced isomerization can be explored.

In the kinetic and spectroscopic measurements of this work, the reactant ions are first thermalized with buffer gas and then analyzed as a function of both trapping time and laser frequency as

$$
\begin{gathered}
\mathrm{X}\left(\mathrm{H}_{2} \mathrm{O}\right)_{n}^{*}+\mathrm{M} \rightarrow \mathrm{X}\left(\mathrm{H}_{2} \mathrm{O}\right)_{n}+\mathrm{M}^{*} \\
\mathrm{X}\left(\mathrm{H}_{2} \mathrm{O}\right)_{n} \stackrel{E_{\mathrm{a}}}{\rightarrow} \mathrm{X}\left(\mathrm{H}_{2} \mathrm{O}\right)_{n-1}+\mathrm{H}_{2} \mathrm{O} \\
\mathrm{X}\left(\mathrm{H}_{2} \mathrm{O}\right)_{n}+h v \rightarrow \mathrm{X}\left(\mathrm{H}_{2} \mathrm{O}\right)_{n-1}+\mathrm{H}_{2} \mathrm{O}
\end{gathered}
$$

where $\mathrm{X}$ is $\mathrm{H}^{+}$or $\mathrm{OH}^{-}$. The third body $\mathrm{M}$ in eq 1 is nothing but a medium for energy transfer, and it can be either $\mathrm{He}$ or $\mathrm{H}_{2}$ because they are light and chemically inert. The method of such cluster bond energy measurements has recently been demonstrated by Lovejoy and Bianco ${ }^{29}$ for small water cluster ions $\mathrm{H}^{+}\left(\mathrm{H}_{2} \mathrm{O}\right)_{3,4}$ using a three-dimensional quadrupole ion trap (Paul trap) at elevated temperatures, i.e., around 300-500 K. The present study represents an extension of their work to larger clusters at lower temperatures.

\section{Experimental and Computational Sections}

A. Experimental. The temperature-variable ion trap mass spectrometer is composed of three differentially pumped vacuum regions, denoted respectively by "Source", "Lens \& Selection", and "Reaction". The heart of this spectrometer is the 22-pole ion trap, as shown schematically in Figure 1. The trap consists of 22 stainless steel rods with a diameter of $1 \mathrm{~mm}$ and a length of $36 \mathrm{~mm}$ equally spaced on an inscribed radius of $5 \mathrm{~mm}$. Pulsed electrodes at the entrance and exit of the trap confine the ions along the axial direction. The design of this trap is identical to that described in detail in ref 9.

We produced the charged water cluster ions by a supersonic expansion of corona-discharged $\mathrm{H}_{2} / \mathrm{H}_{2} \mathrm{O}(99 / 1)$ mixtures through a room-temperature nozzle $(\sim 100 \mu \mathrm{m}$ in orifice diameter $)$ at a backing pressure of $\sim 100$ Torr. The typical discharge voltage used is $700 \mathrm{~V}$ and the resulting discharge current is about 30 $\mu \mathrm{A}$. Downstream the nozzle, the ion beam is skimmed, focused, and bent $90^{\circ}$ toward the first quadrupole mass spectrometer for mass selection. With this mass filter, we select clusters with a specific solvation number $n$ (or $m$ ) out of the mixture $\mathrm{H}^{+}\left(\mathrm{H}_{2} \mathrm{O}\right)_{n}$ 
TABLE 1: Determination of the Dissociation Energies (kcal mol $\left.{ }^{-1}\right)$ of $\mathrm{H}^{+}\left(\mathrm{H}_{2} \mathrm{O}\right)_{4-10}$ and $\mathrm{OH}^{-}\left(\mathrm{H}_{2} \mathrm{O}\right)_{3-7}$ from Their Components at the Mean Trap Temperature $T_{\mathrm{m}}(\mathrm{K})$ and Comparison with Literature Values

\begin{tabular}{|c|c|c|c|c|c|c|}
\hline \multirow[b]{2}{*}{ clusters } & \multicolumn{5}{|c|}{ this work } & \multirow{2}{*}{$\frac{\text { literature values }^{c}}{E_{\text {diss }}}$} \\
\hline & $\overline{T_{\mathrm{m}}}$ & $E_{\mathrm{a}}$ & $\left\langle E_{\mathrm{vib}}\right\rangle^{a}$ & $a k_{\mathrm{B}} T_{\mathrm{m}}{ }^{b}$ & $E_{\text {diss }}$ & \\
\hline $\mathrm{H}^{+}\left(\mathrm{H}_{2} \mathrm{O}\right)_{4}$ & 325 & $10.2 \pm 0.4$ & $6.0 \pm 0.4$ & $0.97 \pm 0.24$ & $17.2 \pm 0.7$ & $17.3,17.4$ \\
\hline $\mathrm{H}^{+}\left(\mathrm{H}_{2} \mathrm{O}\right)_{5}$ & 227 & $6.8 \pm 0.1$ & $4.6 \pm 0.4$ & $0.68 \pm 0.17$ & $12.1 \pm 0.5$ & $12.3,11.1$ \\
\hline $\mathrm{H}^{+}\left(\mathrm{H}_{2} \mathrm{O}\right)_{6}$ & 203 & $4.9 \pm 0.1$ & $5.0 \pm 0.5$ & $0.61 \pm 0.15$ & $10.5 \pm 0.6$ & $11.2,10.7$ \\
\hline $\mathrm{H}^{+}\left(\mathrm{H}_{2} \mathrm{O}\right)_{7}$ & 181 & $4.0 \pm 0.1$ & $4.9 \pm 0.8$ & $0.54 \pm 0.13$ & $9.4 \pm 0.9$ & $10.2,-$ \\
\hline $\mathrm{H}^{+}\left(\mathrm{H}_{2} \mathrm{O}\right)_{8}$ & 164 & $4.0 \pm 0.1$ & $5.0 \pm 0.4$ & $0.49 \pm 0.12$ & $9.5 \pm 0.5$ &,$- \quad-$ \\
\hline $\mathrm{H}^{+}\left(\mathrm{H}_{2} \mathrm{O}\right)_{9}$ & 155 & $4.2 \pm 0.1$ & u.d. & $0.46 \pm 0.11$ & & - \\
\hline $\mathrm{H}^{+}\left(\mathrm{H}_{2} \mathrm{O}\right)_{10}$ & 150 & $4.0 \pm 0.1$ & u.d. & $0.45 \pm 0.11$ & & - \\
\hline $\mathrm{OH}^{-}\left(\mathrm{H}_{2} \mathrm{O}\right)_{3}$ & 323 & $10.3 \pm 0.1$ & $4.9 \pm 0.4$ & $0.96 \pm 0.24$ & $16.2 \pm 0.5$ & 15.5 \\
\hline $\mathrm{OH}^{-}\left(\mathrm{H}_{2} \mathrm{O}\right)_{4}$ & 254 & $6.9 \pm 0.1$ & $4.3 \pm 0.5$ & $0.76 \pm 0.19$ & $12.0 \pm 0.6$ & 11.2 \\
\hline $\mathrm{OH}^{-}\left(\mathrm{H}_{2} \mathrm{O}\right)_{5}$ & 216 & $6.0 \pm 0.1$ & $4.3 \pm 0.6$ & $0.64 \pm 0.16$ & $10.9 \pm 0.7$ & 10.7 \\
\hline $\mathrm{OH}^{-}\left(\mathrm{H}_{2} \mathrm{O}\right)_{6}$ & 203 & $6.3 \pm 0.1$ & $4.6 \pm 0.4$ & $0.61 \pm 0.15$ & $11.5 \pm 0.5$ & 10.4 \\
\hline $\mathrm{OH}^{-}\left(\mathrm{H}_{2} \mathrm{O}\right)_{7}$ & 192 & $6.9 \pm 0.1$ & u.d. & $0.57 \pm 0.14$ & & 9.6 \\
\hline
\end{tabular}

${ }^{a}$ Internal energies of $\mathrm{H}^{+}\left(\mathrm{H}_{2} \mathrm{O}\right)_{9}, \mathrm{H}^{+}\left(\mathrm{H}_{2} \mathrm{O}\right)_{10}$, and $\mathrm{OH}^{-}\left(\mathrm{H}_{2} \mathrm{O}\right)_{7}$ are undetermined (u.d.). ${ }^{b}$ Adopting $a=3 / 2$ and assuming an error of $25 \%$. ${ }^{c}$ Values adapted from thermochemical measurements (refs 15 and 19), following the procedures described in ref 29.

[or $\mathrm{OH}^{-}\left(\mathrm{H}_{2} \mathrm{O}\right)_{m}$ ] coming from the source. After passing through the filter, the selected ions are injected with low kinetic energy into the 22-pole RF ion trap, which contains buffer gas at a fixed pressure and temperature. While being stored, the ions are thermalized by collisions with the cold buffer gas for either kinetic or spectroscopic measurements.

Low temperatures of the ion trap are achieved by using a liquid-nitrogen-cooled coldfinger counter-heated by a heating wire winded around the trap holder. The temperature is measured by two thermocouples (type $E$ ) attached directly to the body of the 22-pole trap. The temperature range thus obtainable is from 77 to $300 \mathrm{~K}$, and above $300 \mathrm{~K}$ (using only the heater without liquid nitrogen). The error in the absolute temperature measurements is about $\pm 1 \mathrm{~K}$, calibrated against the liquid-nitrogen temperature.

Pressures of the buffer gas (either $\mathrm{He}$ or $\mathrm{H}_{2}$ ) inside the 22pole ion trap are measured using a conventional ion gauge outside the storage cell. The ion gauge does not have the accuracy of, for example, a spinning rotor gauge or a Baratron, but in our application, we need only relative pressure readings for determination of the bond energies (see below) and/or in spectroscopic measurements. In assessing the molecular number densities in the trap, we have to include the sensitivity factor of the ion gauge for the used buffer gas [e.g., $f_{\mathrm{He}}=S(\mathrm{He}) /$ $S\left(\mathrm{~N}_{2}\right) \approx 0.15$ and $\left.f_{\mathrm{H} 2}=S\left(\mathrm{H}_{2}\right) / S\left(\mathrm{~N}_{2}\right) \approx 0.4\right]$ and the correction for the Knudsen effect ${ }^{30}$

$$
n_{\mathrm{t}}=\frac{p_{\mathrm{g}}}{k_{\mathrm{B}} \sqrt{T_{\mathrm{t}} T_{\mathrm{g}}}}
$$

where $n_{\mathrm{t}}$ and $T_{t}$ are the number density and the temperature of buffer gas in the trap, $p_{g}$ and $T_{g}$ are the pressure and the temperature of buffer gas in the gauge, respectively, and $k_{\mathrm{B}}$ stands for the Boltzmann factor. The typical value of $n_{\mathrm{t}}$ used in this experiment is $2 \times 10^{13} \mathrm{~cm}^{-3}$, which suggests a collision frequency of $\sim 10^{4} \mathrm{~s}^{-1}$ between the trapped ions and the buffer gas atoms (or molecules).

A RF amplitude (zero-to-peak) of $V_{0}=50 \mathrm{~V}$ from a homebuilt power source ${ }^{31}$ is applied to the 22 rods of the ion trap at the fixed frequency $\Omega / 2 \pi=10 \mathrm{MHz}$. Short dc pulses applied to the retarding electrodes control the entrance and exit of the ions to be investigated. Operating under these conditions, the ion trap allows storage of ions over a wide mass range; it keeps the fragment as well as the parent ions of the reactions described by eqs 2 and 3 for subsequent analysis. In the kinetic measurements, the second quadrupole mass filter located just behind the trap (cf. Figure 1) is set to the parent ion, from which we monitored its decay in a time range up to $200 \mathrm{~ms}$. The typical repetition rate of the ion pulses, generated by the trap entrance gating, in this cluster bond energy measurement is $5 \mathrm{~Hz}$. In the spectroscopic measurements, infrared laser pulses are introduced into the ion trap to pump the collisionally cooled cluster ions to the first vibrationally excited state at a repetition rate of 20 $\mathrm{Hz}$. The laser beam with an energy of $\sim 2 \mathrm{~mJ} /$ pulse is generated by difference frequency mixing of the $\mathrm{Nd}$ :YAG fundamental photon $(1064 \mathrm{~nm})$ and the $\sim 760 \mathrm{~nm}$ output of a tunable dye laser using a $\mathrm{LiNbO}_{3}$ crystal. After vibrational excitation, the product ions are extracted from the ion trap and selected by the second mass filter to obtain the infrared action spectra. The typical storage time of the ions in the trap before the laser excitation is $10 \mathrm{~ms}$. The ion signals in both experiments are detected by either a Daly detector (for positive ions) or an electron multiplier (for negative ions) operated in an ion counting mode.

We emphasize that, compared to the Paul trap, our 22-pole storage cell has a wide field-free region, which effectively avoids $\mathrm{RF}$ excitation and collisional defocusing of the trapped ions. The feature is critically important for experiments conducted at lower temperatures for larger and/or less strongly bound clusters. ${ }^{10}$ Lovejoy and Bianco ${ }^{29}$ have examined the effect of the applied trap driving voltage on the measured decomposition rate constants for $\mathrm{H}^{+}\left(\mathrm{H}_{2} \mathrm{O}\right)_{4}$ and other cluster ion systems. Their results show that the RF heating effect is nonnegligible at the parameter $q_{z}>0.3$ when using the quadrupole ion trap as a storage cell. For the multipole ion trap, Gerlich ${ }^{7}$ has defined an adiabaticity parameter

$$
\eta=2 n(n-1) \frac{e V_{0}}{m r_{0}{ }^{2} \Omega^{2}} \hat{\mathrm{r}}^{n-2}
$$

which reduces to $q_{z}$ at $2 n=4$. Adopting $V_{0}=50 \mathrm{~V}, \Omega / 2 \pi=$ $10 \mathrm{MHz}$, the center-to-pole distance of $r_{0}=5 \mathrm{~mm}$, the pole number of $2 n=22$, and the maximum turning radius of $\hat{r}=$ $r / r_{0}=0.8$ for the 22-pole trap used in this experiment, we have $\eta \approx 0.02$ at $m / e=70$. Because $\eta$ is inversely proportional to $m$, the values of this parameter for other ions $(m / e>70)$ listed in Table 1 are all less than 0.02 , which is well below the safe operation limit $(\eta<0.3)$ of the multipole RF ion trap. ${ }^{7}$

B. Computational. Theoretically calculated vibrational frequencies and molecular structures are used in assessment of cluster internal energies as well as for spectral assignment. The 

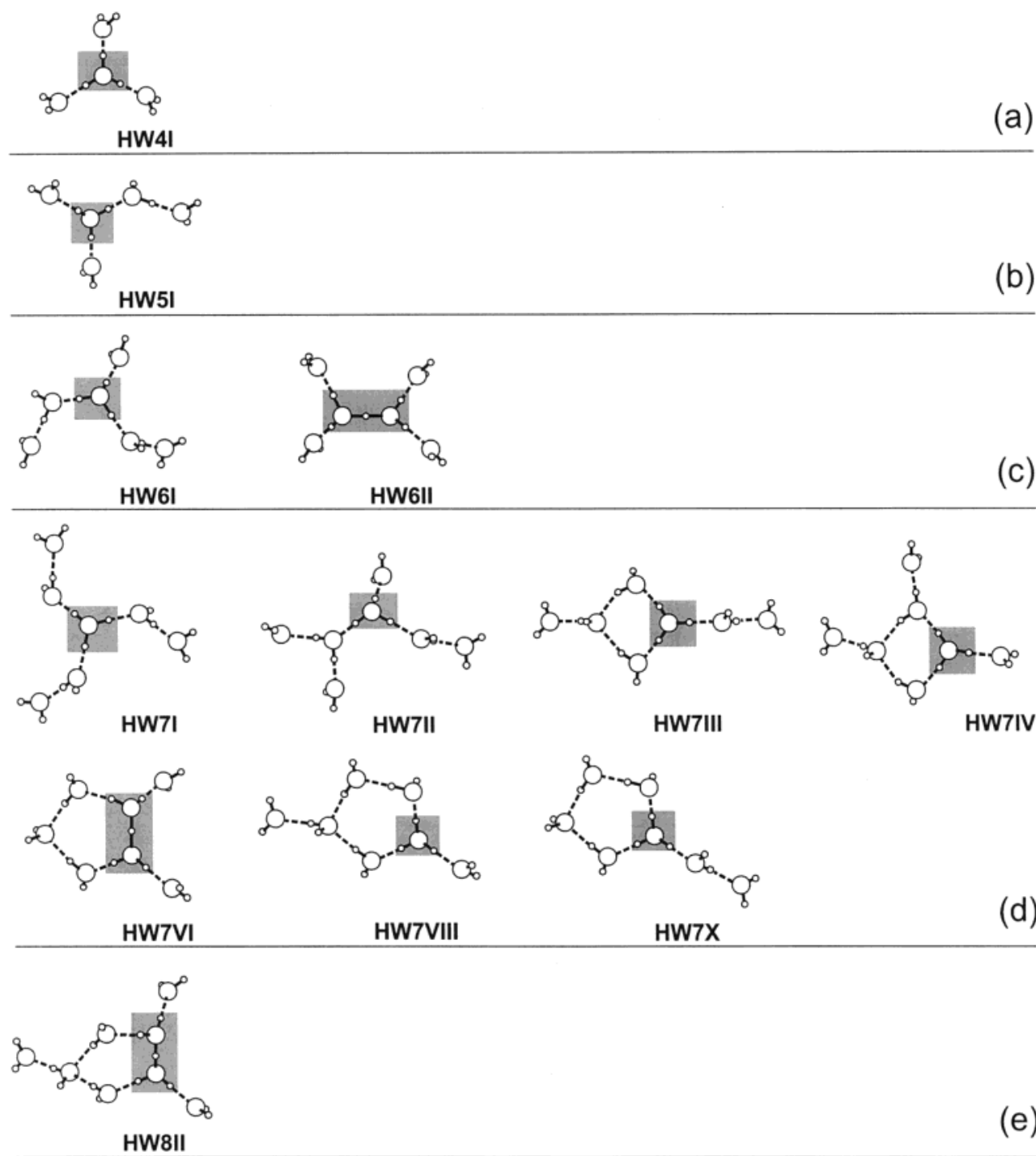

(e)

Figure 2. Low-energy isomers of $(a) \mathrm{H}^{+}\left(\mathrm{H}_{2} \mathrm{O}\right)_{4}$, (b) $\mathrm{H}^{+}\left(\mathrm{H}_{2} \mathrm{O}\right)_{5}$, (c) $\mathrm{H}^{+}\left(\mathrm{H}_{2} \mathrm{O}\right)_{6}$, (d) $\mathrm{H}^{+}\left(\mathrm{H}_{2} \mathrm{O}\right)_{7}$, and (e) $\mathrm{H}^{+}\left(\mathrm{H}_{2} \mathrm{O}\right)_{8}$. The $\mathrm{O}$ and $\mathrm{H}$ atoms are represented by large open and small open circles, respectively, and the ion cores (either $\mathrm{H}_{3} \mathrm{O}^{+}$or $\mathrm{H}_{5} \mathrm{O}_{2}{ }^{+}$) are shaded for clarity. Shown here are only isomers that have been previously identified in a supersonic expansion (ref 18).

calculations, based on the density functional theory (DFT), are performed using the commercial Gaussian 98 package. ${ }^{32}$ Utilizing a standard analytical gradient method, geometries of the cluster ions were optimized without imposing any symmetry constraints at the B3LYP level of computation with the $6-31+\mathrm{G}^{*}$ basis set (denoted as B3LYP/6-31+G*).

A large number of $\mathrm{H}^{+}\left(\mathrm{H}_{2} \mathrm{O}\right)_{4-10}$ and $\mathrm{OH}^{-}\left(\mathrm{H}_{2} \mathrm{O}\right)_{3-7}$ potential minima are located in the course of the computation. They correspond to isomers of chainlike, four-membered ring, fivemembered ring, double ring, and cage-like structures. The structures and energetics of these isomers have been previously reported. ${ }^{18,23}$ We depict in Figure 2 only the isomeric structures of $\mathrm{H}^{+}\left(\mathrm{H}_{2} \mathrm{O}\right)_{4-8}$ that have been identified in a corona-discharged supersonic expansion at an estimated cluster temperature of 170 K. ${ }^{16-18}$ For clusters of $n \leq 6$, they are predominantly the chainlike structures (namely, HW4I, HW5I, HW6I, and HW6II), whereas at $n \geq 7$, ring structures (HW7III, HW7IV, HW7VI, HW7VIII, HW7X, and HW8II) exist. Such a preference of five-membered ring formation in $\mathrm{H}_{3} \mathrm{O}^{+}\left(\mathrm{H}_{2} \mathrm{O}\right)_{n}$ stands as an interesting contrast to its structural analogue $\mathrm{NH}_{4}{ }^{+}\left(\mathrm{H}_{2} \mathrm{O}\right)_{n},{ }^{33}$ of which the formation of symmetric fourmembered rings is strongly favored.

\section{Results and Discussions}

A. Kinetic Measurements. For bond energy measurements temperature-dependent decays of the cluster ions, in He buffer gas were recorded, as described by eq 2 . At higher buffer gas temperatures $(>120 \mathrm{~K})$, we observed a simple exponential decay of the stored parent ions as the internal energy of some of them comes close to the dissociation limit, and the collisions with the buffer gas atoms help to overcome this barrier. At lower temperatures $(77-120 \mathrm{~K})$, a part of the cluster ions are seen to fragment due to collisions with the buffer gas atoms when they enter the trap. The fragmentation, however, slows down after $20 \mathrm{~ms}$ of the storage (with a buffer gas pressure of $p_{\mathrm{g}}=8 \times$ $10^{-5}$ Torr) and the number of the detected parent ions gradually stabilizes. In the first $20 \mathrm{~ms}$, the ions undergo about 200 collisions. It is therefore safe to assume that the ions are in thermal equilibrium with the buffer gas at this time. It also suggests that the time scale for the cluster ions to be completely equilibrated in internal (rotational and vibrational) modes is $\sim 20 \mathrm{~ms}$.

As an example of the measurements done, we show in Figure 3 a the exponential decay of $\mathrm{H}^{+}\left(\mathrm{H}_{2} \mathrm{O}\right)_{5}$ (mass 91) in He buffer gas at 8 different trapping temperatures $\left(T_{\mathrm{t}}\right)$ in the range 190$240 \mathrm{~K}$. The single exponential decays are indications that the 

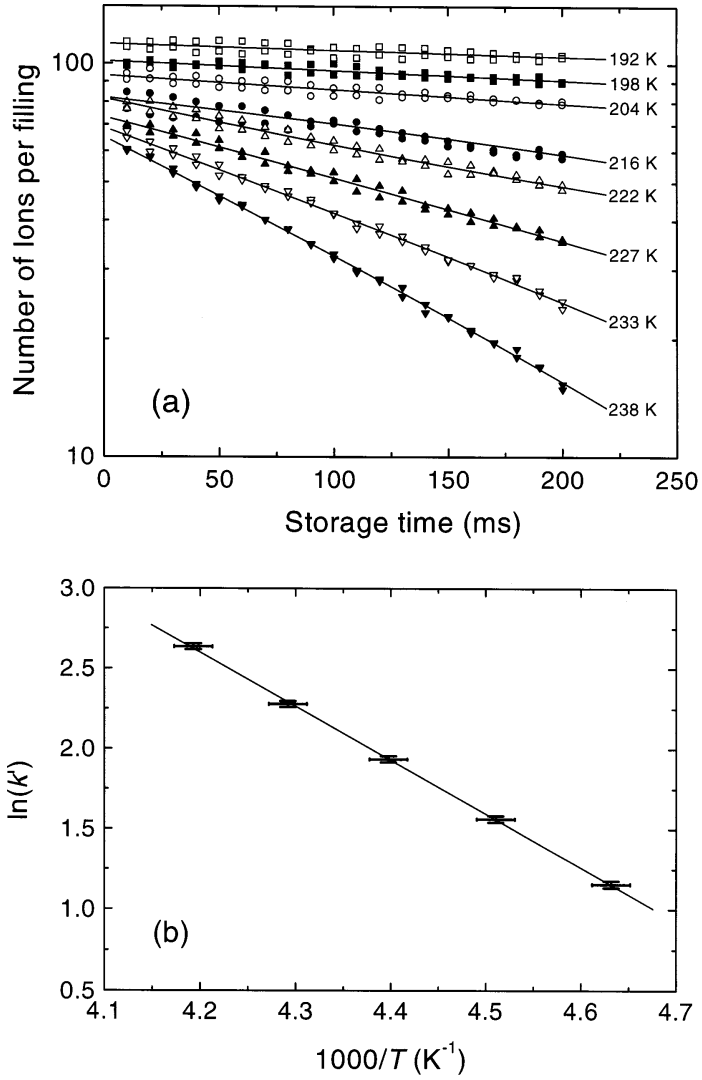

Figure 3. (a) Dissociation of $\mathrm{H}^{+}\left(\mathrm{H}_{2} \mathrm{O}\right)_{5}$ in the temperature-variable 22-pole ion trap at various temperatures. (b) Dissociation rate constants of $\mathrm{H}^{+}\left(\mathrm{H}_{2} \mathrm{O}\right)_{5}$ as a function of ion trap temperature. The linear line represents the best fit of the experimental data to the Arrhenius equation.

ensemble is in thermal equilibrium to a precision of about $1 \mathrm{~K}$ because otherwise the decays would be curved corresponding to a thermalization happening on the time scale of $200 \mathrm{~ms}$. We began the trapping with around 100 cluster ions per filling, which may vary between 70 and 110 , depending on the trapping conditions used (for example, different buffer gas temperatures and ion energies). Each data point in the figure consists of an average of 200 ion trap fillings. The multiple data points given for each temperature and storage time come from several iterations to check for the primary beam stability. Exponential fits to these curves give the pseudo-first-order rate constants ranging from $k^{\prime}=0.31 \mathrm{~s}^{-1}$ for $T_{\mathrm{t}}=192 \mathrm{~K}$ to $k^{\prime}=7.21 \mathrm{~s}^{-1}$ for $T_{\mathrm{t}}=238 \mathrm{~K}$. The statistical errors obtained from the fits, as shown in Figure 3b, are around $1 \%$ for the faster decays but become much larger (approximately 20\%, not shown) for the slower decays at lower temperatures $\left(T_{\mathrm{t}}<200 \mathrm{~K}\right)$. Such obtained temperature-dependent rate constants follow the wellknown Arrhenius relation, $k^{\prime}=A \exp \left(-E_{\mathrm{a}} / k_{\mathrm{B}} T\right)$, where

$$
E_{\mathrm{a}}=-k_{\mathrm{B}} \frac{\partial \ln \left(k^{\prime}\right)}{\partial(1 / T)}
$$

is given as the linear slope in Figures $3 b$ and $4 a$.

In making these plots, we have taken into account the change of the buffer gas number density $n_{\mathrm{t}}$ with trap temperature as explained in eq 4. To limit the temperature range for later analysis, we considered only the $\sim 5$ highest temperature points and made a fit weighted by experimental errors. Another reason to consider only these points is that the residual reactive loss of the water cluster ions (with a rate constant of $\sim 0.1 \mathrm{~s}^{-1}$ ) due to contaminants in the vacuum chamber influences less the
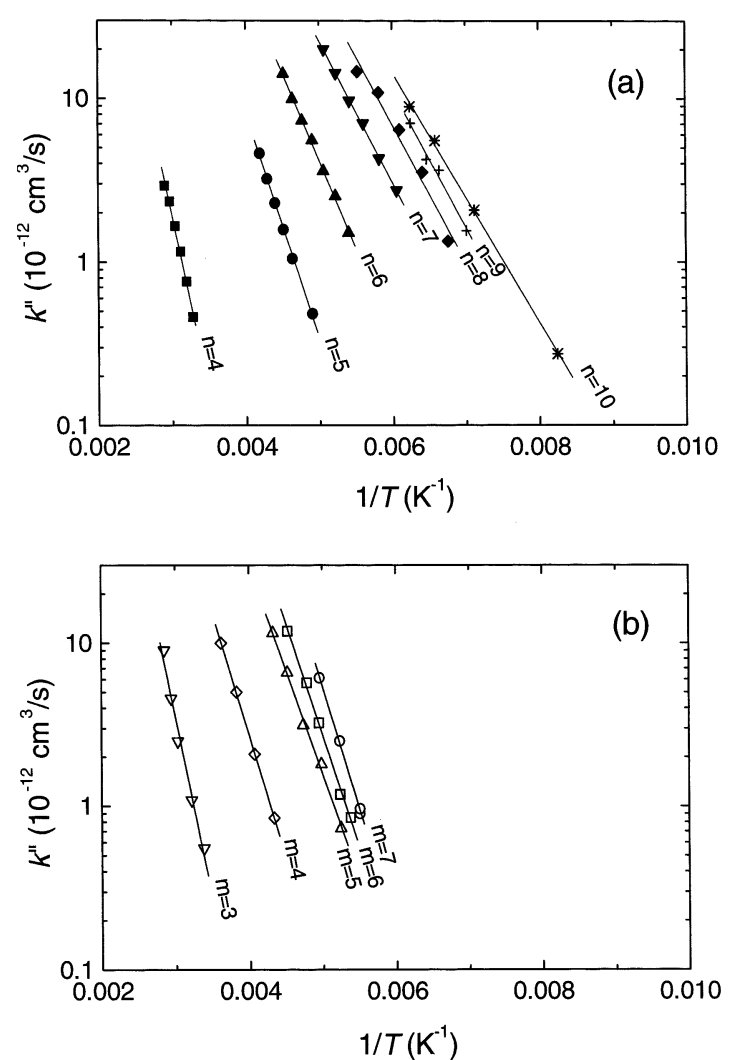

Figure 4. Dependence of the dissociation rate constants of (a) $\mathrm{H}^{+}\left(\mathrm{H}_{2} \mathrm{O}\right)_{n}, n=4-10$, and (b) $\mathrm{OH}^{-}\left(\mathrm{H}_{2} \mathrm{O}\right)_{m}, m=3-7$, on the ion trap temperature. The linear lines represent the best fits of the experimental data to the Arrhenius equation.

measurements involving faster decays (or a larger $k^{\prime}$ ). From the fit in Figure 3b, we obtain a slope of $-(3407 \pm 50)$ in units of Kelvin, which corresponds to an activation energy of $E_{\mathrm{a}}=6.8$ $\pm 0.1 \mathrm{kcal} \mathrm{mol}^{-1}$ for the $\mathrm{H}^{+}\left(\mathrm{H}_{2} \mathrm{O}\right)_{5}$ cluster ion.

From eq 6, we see that it is not important for the determination of $E_{\mathrm{a}}$ to know the exact pressure of $\mathrm{He}$ in the 22-pole trap. Rather, it is the temperature dependence of $k^{\prime}$ that matters, because the absolute number density $n_{\mathrm{t}}$ finally cancels out when taking the logarithm and the derivative of $k^{\prime}$ in relation 6 . In this experiment, we were working in (or very near to) the lowpressure limit, where the pseudo-first-order rate constant $k^{\prime}$ is proportional to the He number density $n_{\mathrm{t}}$. Tests for the linearity $k^{\prime}=k^{\prime \prime} n_{\mathrm{t}}$, where $k^{\prime \prime}$ is the second-order rate constant, have been made independently by varying the pressures. With twice the pressure, for example, a factor of 2 increase in $k^{\prime}$ was indeed observed. This gives us the magnitude of the $k^{\prime \prime}$ to be around $1 \times 10^{-12} \mathrm{~cm}^{3} \mathrm{~s}^{-1}$ (cf. Figure 4), but we should allow for an uncertainty factor of 2 for the result because of the limited accuracy of the ion gauge in the He pressure measurements.

To obtain the cluster bond energy, or the cluster dissociation energy $E_{\text {diss }}$, from the kinetics measurements as described above, we use the relation ${ }^{29,34}$

$$
E_{\mathrm{diss}}=E_{\mathrm{a}}+\left\langle E_{\mathrm{vib}}\right\rangle+a k_{\mathrm{B}} T_{\mathrm{m}}
$$

which applies to the special case of weak collisions and low pressures; that is, the change of internal energy by one collision is small compared to the total mean internal energy $\left\langle E_{\mathrm{vib}}\right\rangle$, and if one collision lifts the ionic cluster over the dissociation threshold $E_{\text {diss }}$, it decays faster than the next collision can take place. The correction term $a k_{\mathrm{B}} T_{\mathrm{m}}$ in this relation accounts for 
the average energy transferred from the He bath to those clusters sitting just below their dissociation limit and irreversibly lifted over the dissociation barrier by collisions with the He atoms. The temperature dependence of the factors such as the rate coefficient for collision with buffer gas and the collision efficiency are included in this term. ${ }^{34}$ Lovejoy and Bianco ${ }^{29}$ have carefully examined this term for a variety of (small) cluster ions and found the value of the parameter $a$ may vary from -1 to +3 , depending on the ionic species, cluster size and experimental conditions.

Theoretical evaluation of $\left\langle E_{\mathrm{vib}}\right\rangle$ is based on the vibrational frequencies provided by the B3LYP/6-31+G* level of computation. We calculate the internal energies $\left\langle E_{\mathrm{vib}}\right\rangle$ at the median temperature $\left(T_{\mathrm{m}}\right)$ of the temperature range of the ion decay measurements. Continuing with $\mathrm{H}^{+}\left(\mathrm{H}_{2} \mathrm{O}\right)_{5}$ as the example, this would be $T_{\mathrm{m}}=227 \mathrm{~K}$ and the calculated vibrational energy is $\left\langle E_{\mathrm{vib}}\right\rangle=4.6 \mathrm{kcal} \mathrm{mol}^{-1}$ for the isomer HW5I, which is the only species identified in our previous spectroscopic experiments (cf. Table 1). For the correction term $a k_{\mathrm{B}} T_{\mathrm{m}}$, Lovejoy and Bianco 29 have suggested two average values, $a=1.2$ and 1.8, obtained respectively from the harmonic and free rotor treatments for the torsional motions of the clusters. These two numbers give an average difference of $\sim 1 \mathrm{kcal} \mathrm{mol}^{-1}$ between the predicted and the literature values of $E_{\mathrm{diss}}$ in the temperature range $300-500 \mathrm{~K}$. As in our case, except that of $\mathrm{H}^{+}\left(\mathrm{H}_{2} \mathrm{O}\right)_{4}$ and $\mathrm{OH}^{-}\left(\mathrm{H}_{2} \mathrm{O}\right)_{3}$, the ion trap is typically maintained at a temperature less than $250 \mathrm{~K}$, and the contribution from this correction term to $E_{\text {diss }}$ is significantly smaller. We therefore adopt $a=1.5$ (assuming an error of 25\%), namely, only taking into account the three external degrees of freedom of the free neutral water molecule as the first-order approximation in the present treatment.

With the values given above, we obtain a dissociation energy $E_{\text {diss }}=12.1 \mathrm{kcal} \mathrm{mol}^{-1}$ for $\mathrm{H}^{+}\left(\mathrm{H}_{2} \mathrm{O}\right)_{5}$. The standard deviation deduced from the activation energy fit in Figure $3 b$ is $\sim 0.1$ $\mathrm{kcal} \mathrm{mol}^{-1}$, but we have some uncertainties in the determination of $T_{\mathrm{m}}$, which in turn has a significant influence on the calculation of $\left\langle E_{\mathrm{vib}}\right\rangle$. In addition to that, we have some uncertainties in the DFT computation of the vibrational frequencies (especially the lower-frequency modes, which are crucial in the temperature range considered here) and also the uncertainties for the coexistence of more than one isomer in the cluster production. A combination of all these factors makes precise determination of $\left\langle E_{\text {vib }}\right\rangle$ very difficult. So, we would rather assume our total error in the bond energy assessment to be of the order of 0.5 $\mathrm{kcal} \mathrm{mol}{ }^{-1}$ for this particular cluster ion, $\mathrm{H}^{+}\left(\mathrm{H}_{2} \mathrm{O}\right)_{5}$.

For $\mathrm{H}^{+}\left(\mathrm{H}_{2} \mathrm{O}\right)_{n}$ of $n=6-8$, rather than to consider only the lowest energy isomer as in the cases of $n=4$ and 5, we choose to take into account all isomers that have been identified in our previous experiments for the calculation of $E_{\text {diss. }}$. The structures of these isomers for each cluster size are depicted in Figure $2 \mathrm{c}-\mathrm{e}$. There are seven possible isomers for $\mathrm{H}^{+}\left(\mathrm{H}_{2} \mathrm{O}\right)_{7}$, for example, and we have taken the average value of $\left\langle E_{\mathrm{vib}}\right\rangle$ for all of them in the calculation. As for the clusters with $n=9$ and 10 , identification of the structural isomers in a supersonic expansion has not yet been accomplished. A reasonable assumption to make is that their structures closely resemble those of $n=7$ and 8, namely they contain only one or two fivemembered rings rather than compact cages. It is clear that the calculation for the vibrational energies $\left\langle E_{\mathrm{vib}}\right\rangle$ of larger clusters would become much less accurate because of the exponentially increasing manifold of possible isomers. We expect the total error in our bond energy assessment to be $\sim 1 \mathrm{kcal} \mathrm{mol}^{-1}$ for these high-mass clusters.
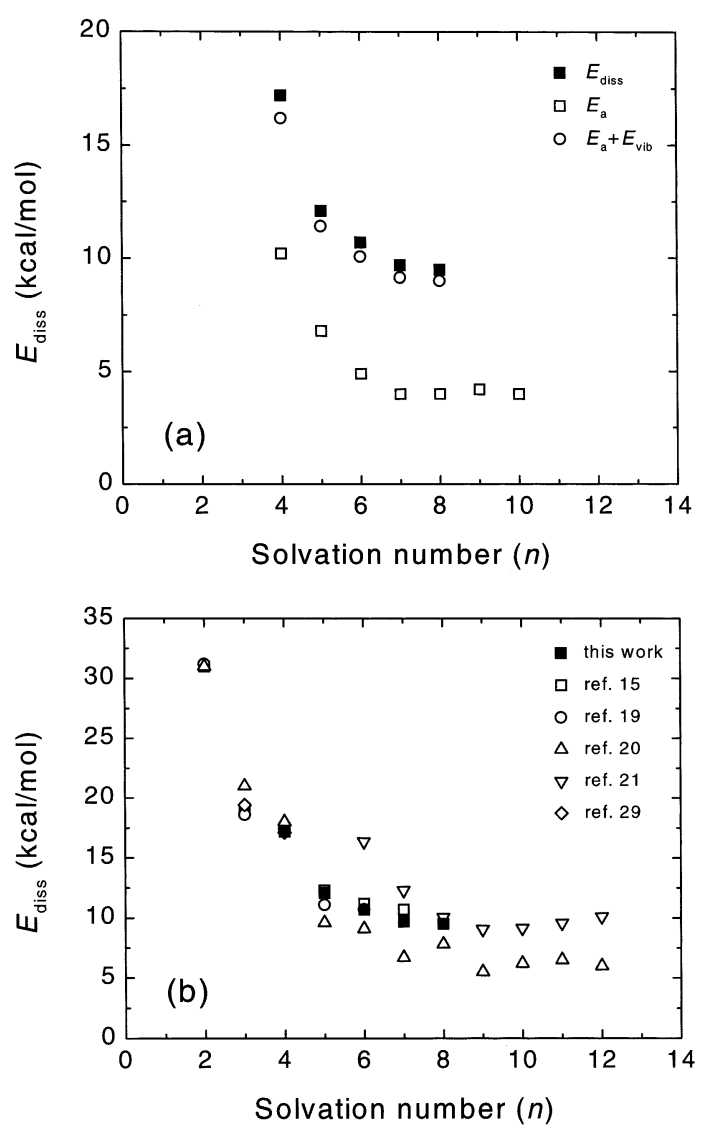

Figure 5. (a) Variations of the measured dissociation energies and their components with the solvation number of $\mathrm{H}^{+}\left(\mathrm{H}_{2} \mathrm{O}\right)_{n}$. (b) Comparison of the dissociation energies $E_{\text {diss }}$ obtained in this work with literature values for $\mathrm{H}^{+}\left(\mathrm{H}_{2} \mathrm{O}\right)_{n}$ at various $n$.

We summarize in Table 1 and Figure 5 the measured and the DFT-calculated components of $E_{\text {diss }}$ for $\mathrm{H}^{+}\left(\mathrm{H}_{2} \mathrm{O}\right)_{n}$ of $n=$ 4-10. Figure 5a shows the dissociation energy $E_{\text {diss }}$ as a sum of the activation energy $E_{a}$, the vibrational energy at the median temperature $\left\langle E_{\mathrm{vib}}\right\rangle$, and the small correction term $a k_{\mathrm{B}} T_{\mathrm{m}}$. Going from the large to the small solvation number $n$, the dissociation energy for $\mathrm{H}^{+}\left(\mathrm{H}_{2} \mathrm{O}\right)_{n}$ increases steadily, beginning in the regime of bulk water with an evaporation enthalpy of $\sim 10 \mathrm{kcal} \mathrm{mol}^{-1} .35$ At $n=4$, the otherwise smooth sequence of the bond energies makes a noticeable jump. Such a jump is expected if we examine the structure of the most stable isomer for $\mathrm{H}^{+}\left(\mathrm{H}_{2} \mathrm{O}\right)_{4}$, i.e., $\mathbf{H W 4 I}$, which is symmetric and consists of $\mathrm{H}_{3} \mathrm{O}^{+}$core with three water molecules surrounding it. For this cluster isomer, the first solvation shell of $\mathrm{H}_{3} \mathrm{O}^{+}$has been just filled, and all of the water molecules are predominantly bound to the central ion by strong charge-dipole interactions rather than hydrogen bonding as is the case for water molecules in the outer solvation shells. Hence, not surprisingly, it would take relatively more energy $(17.2 \pm$ $\left.0.8 \mathrm{kcal} \mathrm{mol}^{-1}\right)$ to detach a water molecule from $\mathrm{H}^{+}\left(\mathrm{H}_{2} \mathrm{O}\right)_{4}$. This shell filling effect has been observed in the earliest experiment of Kebarle and co-workers. ${ }^{15}$

In Table 1, we also include the results of $\mathrm{OH}^{-}\left(\mathrm{H}_{2} \mathrm{O}\right)_{3-7}$ for comparison with literature values. The listed internal energies of $\mathrm{OH}^{-}\left(\mathrm{H}_{2} \mathrm{O}\right)_{3-6}$ are averages of the $\left\langle E_{\mathrm{vib}}\right\rangle$ of DFT-predicted low-energy isomers. We may give an uncertainty of around \pm 1 $\mathrm{kcal} \mathrm{mol}^{-1}$ for these values because of the lack of the knowledge of isomers that make contribution to our measurements. ${ }^{23}$ Analogous to the case of $\mathrm{H}^{+}\left(\mathrm{H}_{2} \mathrm{O}\right)_{n}$, the cluster bond energy of $\mathrm{OH}^{-}\left(\mathrm{H}_{2} \mathrm{O}\right)_{m}$ shows a steady decrease from $16.2 \mathrm{kcal} \mathrm{mol}^{-1}$ of $m=3$ to $11.5 \mathrm{kcal} \mathrm{mol}^{-1}$ of $m=6$. However, unlike the cation counterparts, no distinct shell effect is detected for the hydroxide 


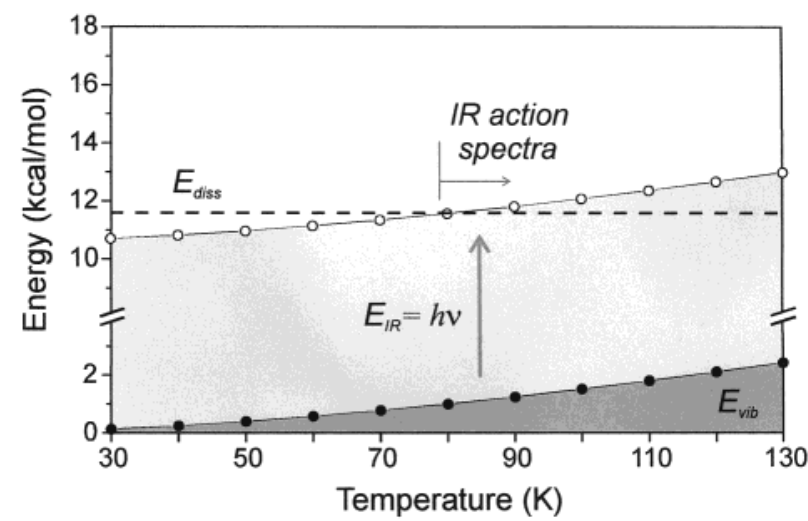

Figure 6. Energy diagram of isomer HW6II of the $\mathrm{H}^{+}\left(\mathrm{H}_{2} \mathrm{O}\right)_{6}$ cluster. The $E_{\mathrm{vib}}$ area represents the DFT-calculated internal energies at different temperatures, $E_{\mathrm{IR}}$ is the average photon energy used in this work $(\sim 10.6$ $\mathrm{kcal} \mathrm{mol}^{-1}$ ), and $E_{\text {diss }}$ is the measured dissociation energy. The infrared action spectra are recorded at temperatures above $77 \mathrm{~K}$.

ion, where filling of the first solvation shell is expected to complete at $m=3$ for $\mathrm{OH}^{-}\left(\mathrm{H}_{2} \mathrm{O}\right)_{m}$, according to Meot-Ner and Speller. ${ }^{19}$

A comparison of our results with other literature values ${ }^{15,19,20,21,29}$ is shown in Figure 5b. However, to compare our measured bond energies $E_{\text {diss }}$ with the bond enthalpies $\Delta$ $H_{n-1, n}^{0}(\mathrm{~T})$ as given in most publications from thermochemical measurements, we have to calculate the difference in total energies (i.e., translational, rotational, and vibrational energies) of the products and reactants for the dissociation [eq 2] at the given temperature $T$. Such a conversion based on theoretical heat capacities has been performed (see refs 36 and 37 for details of the calculation), although it is found that the difference between the bond enthalpy and the bond energy is small, typically less than $0.5 \mathrm{kcal} \mathrm{mol}^{-1}$. As shown in Figure $5 \mathrm{~b}$, the agreement in $E_{\text {diss }}$ among different measurements is very good (within $1 \mathrm{kcal} \mathrm{mol}^{-1}$ ) except that of ref 20, where the reported bond energies are systematically too low, whereas the bond energies at $n=6$ and 7 from ref 21 seem to be too high in comparison to ours and other measured values.

B. Spectroscopic Measurements. To obtain the infrared spectra of gas-phase cluster ions, one always requires an intense and stable precursor beam during the entire data-recording period (typically $4 \mathrm{~h}$ ). For $\mathrm{H}^{+}\left(\mathrm{H}_{2} \mathrm{O}\right)_{n}$, as determined by the expansion conditions of our ion source, the size distribution of the precursors in this experiment is often peaking at $n=6$ and 7. We therefore started the spectroscopic measurement with the protonated water hexamer for the fundamental free-OH stretches over the frequency range $3620-3760 \mathrm{~cm}^{-1}$. Because one quantum of the free-OH vibration corresponds to an energy of $E_{\mathrm{IR}} \approx 10.6 \mathrm{kcal} \mathrm{mol}^{-1}$, which is typically less than the dissociation energy of $E_{\mathrm{diss}} \approx 12 \mathrm{kcal} \mathrm{mol}^{-1}$ for most of the cluster ions shown in Table 1 , some internal energy must be required for the dehydration of cluster ions under low-temperature conditions when only single photons are absorbed by the individual ions during each trapping cycle. Figure 6 illustrates the correlations of the total vibrational energy $\left\langle E_{\mathrm{vib}}\right\rangle$ and the ion temperature and the dissociation threshold of $\mathrm{H}^{+}\left(\mathrm{H}_{2} \mathrm{O}\right)_{n}$ using the cluster isomer HW6II (Figure 2c) as an example.

We employ $\mathrm{H}_{2}$, rather than $\mathrm{He}$, as the buffer gas in the spectroscopic measurement. This is because the hydrogen molecule contains one internal degree of freedom, which makes it easier to accept the vibrational energies of the trapped ions than the helium atom in a cold environment. Moreover, hydrogen is lighter than helium and so collisional excitation of

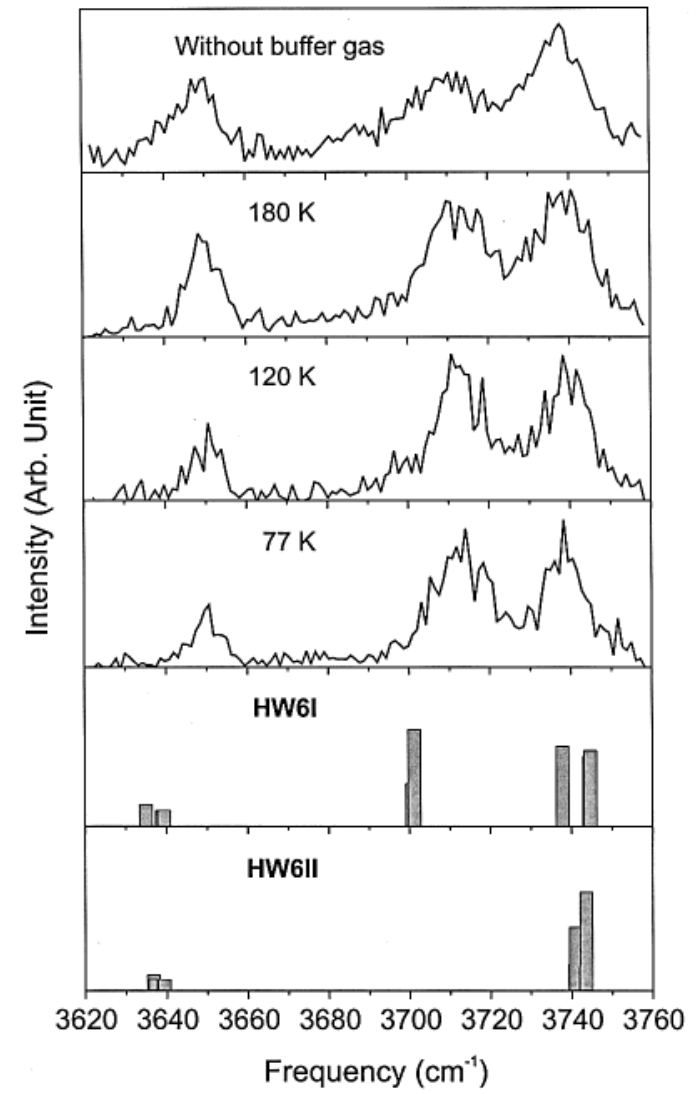

Figure 7. Temperature-dependent vibrational predissociation spectra of $\mathrm{H}^{+}\left(\mathrm{H}_{2} \mathrm{O}\right)_{6}$ acquired at 77,120 , and $180 \mathrm{~K}$ in the free-OH stretch region. They are compared to the spectrum acquired without buffer gas in the trap held at room temperature. Shown at the bottom are the calculated stick spectra of two lowest-energy isomers, HW6I and HW6II (cf. Figure 2c).

the trapped species can be minimized. In this experiment, the cluster ions are typically confined in the ion trap for $10 \mathrm{~ms}$ before the laser excitation. With the buffer gas density of the order of $n_{\mathrm{t}} \approx 10^{13} \mathrm{~cm}^{-3}$ as described earlier for He, more than 100 collisions occur between the trapped ion and the $\mathrm{H}_{2}$ molecules. These stored cluster ions are therefore expected to thermalize with their surroundings before the spectroscopic measurements.

Figure 7 displays the infrared spectra of $\mathrm{H}^{+}\left(\mathrm{H}_{2} \mathrm{O}\right)_{6}$ at $77-$ $180 \mathrm{~K}$ in the free-OH stretching region. They are compared in parallel to the first spectrum (the topmost) acquired at room temperature without the buffer gas. The temperature of the cluster ions trapped under such collision-free conditions is roughly $200 \mathrm{~K}$, as estimated from the measured metastable dissociation rates fitted to an evaporative ensemble model. ${ }^{38,39}$ Notably, all of the spectra show 3 distinct features centered at $v_{0}=3740,3715$, and $3650 \mathrm{~cm}^{-1}$, corresponding respectively to the asymmetric, the 2-coordinated, and the symmetric free$\mathrm{OH}$ stretches of the water molecules in either the first solvation shell or the second solvation shell of the $\mathrm{H}_{3} \mathrm{O}^{+}$or $\mathrm{H}_{5} \mathrm{O}_{2}{ }^{+}$ion core. ${ }^{18}$ The full widths at half-maximum (fwhm) of these three absorption bands are all larger than $15 \mathrm{~cm}^{-1}$, but they decrease significantly when $\mathrm{H}_{2}$ is introduced into the storage cell. An average reduction factor of 1.7 is found for the spectrum acquired at $200 \mathrm{~K}$ compared to that at $77 \mathrm{~K}$. Table 2 lists the spectral assignment, vibrational frequencies, and bandwidths of the individual peaks observed at three different bath temperatures in comparison to those obtained at room temperature without $\mathrm{H}_{2}$ buffer gas. 
TABLE 2: Comparison of the Observed Band Centers and Widths $\left(\mathrm{cm}^{-1}\right)$ at Various Ion Trap Temperatures $(\mathrm{K})^{a}$

\begin{tabular}{|c|c|c|c|c|c|c|}
\hline \multirow[b]{2}{*}{ temp. } & \multicolumn{2}{|c|}{$\mathrm{s}-\mathrm{OH}_{2}$ stretch } & \multicolumn{2}{|c|}{ f-OH stretch } & \multicolumn{2}{|c|}{$\mathrm{a}-\mathrm{OH}_{2}$ stretch } \\
\hline & $v_{0}$ & fwhm & $v_{0}$ & fwhm & $v_{0}$ & fwhm \\
\hline 77 & 3650.5 & 8.0 & 3713.0 & 15.6 & 3739.3 & 11.7 \\
\hline 120 & 3650.2 & 8.8 & 3712.0 & 16.3 & 3738.8 & 13.7 \\
\hline 180 & 3649.7 & 10.8 & 3711.1 & 19.4 & 3738.6 & 14.6 \\
\hline$\sim 200$ & 3648.3 & 17.0 & 3710.5 & 25.0 & 3739.2 & 15.3 \\
\hline
\end{tabular}

${ }^{a}$ The notations s- $\mathrm{OH}_{2}$ and a- $\mathrm{OH}_{2}$ stand respectively for the symmetric and asymmetric stretches of $\mathrm{H}_{2} \mathrm{O}$ acting as a single-proton acceptor, and the $\mathrm{f}-\mathrm{OH}$ stands for the free- $\mathrm{OH}$ stretch of 2-coordinated $\mathrm{H}_{2} \mathrm{O}$ acting as a single-proton donor and single-proton acceptor (cf. Figure 1).

Shown at the bottom of Figure 7 are the DFT-calculated stick diagrams of two isomers (HW6I and HW6II) for comparison with the experimental spectra. These two isomers are the lowest in energy among all stable structures of $\mathrm{H}^{+}\left(\mathrm{H}_{2} \mathrm{O}\right)_{6}$ and are centered by the $\mathrm{H}_{3} \mathrm{O}^{+}$and the $\mathrm{H}_{5} \mathrm{O}_{2}{ }^{+}$entity, respectively (cf. Figure 2). Identification of them has been successful in a coronadischarged supersonic expansion in our previous experiment. ${ }^{18}$ Because the source condition used by this new spectrometer is similar to that of the room-temperature 8-pole ion trap apparatus used in ref 18, we expect that these two chainlike isomers exist in the present 22-pole ion trap mass spectrometer as well.

We note that in Figure 7 the shifts of the spectral band centers with temperature are not significant enough $\left(<1 \mathrm{~cm}^{-1}\right)$ to lead to any conclusive remarks. In comparison, the cooling effect can be seen more readily in the change of the widths of the absorption bands. As listed in Table 2, the fwhm of the absorptions decreases roughly by factors of 1.2 and 1.1, respectively, as the bath temperature is lowered consecutively from 180 to $120 \mathrm{~K}$ and from 120 to $77 \mathrm{~K}$. Overall, the fwhm decreases by a factor of roughly 1.3 across a temperature change range of $\Delta T=-113 \mathrm{~K}$. Such a bandwidth reduction is smaller than we expected because an fwhm of less than $10 \mathrm{~cm}^{-1}$ has already been observed for these bands at an estimated cluster temperature of $\sim 140 \mathrm{~K}$ under collision-free conditions. ${ }^{18} \mathrm{We}$ attribute this unsatisfactory result to inefficient cooling of the internal rotations of the solvent water molecules attached to the $\mathrm{H}_{3} \mathrm{O}^{+}$or $\mathrm{H}_{5} \mathrm{O}_{2}{ }^{+}$ion core.

The internal rotation within an ionic cluster was first observed by Price et al. ${ }^{40}$ for $\mathrm{H}^{+}\left(\mathrm{NH}_{3}\right)_{n}$ generated by a supersonic expansion and stored in an empty octopole ion trap. From the rotation-vibration transitions resulting from a rotation of the $\mathrm{NH}_{3}$ subgroups about its local $C_{3}$ axis, they estimated a $\boldsymbol{J}$ rotational temperature of $\sim 20 \mathrm{~K}$ and a $\boldsymbol{K}$ rotational temperature of $\sim 45 \mathrm{~K}$ for these jet-cooled cluster ions. We have previously also observed the subbands of the asymmetric free-OH stretch transitions due to the nearly free internal rotation of $\mathrm{H}_{2} \mathrm{O}$ attached to the $\mathrm{NH}_{4}{ }^{+}$core in $\mathrm{NH}_{4}{ }^{+}\left(\mathrm{H}_{2} \mathrm{O}\right)_{n}{ }^{41}$ These subbands have a characteristic spacing of $55 \mathrm{~cm}^{-1}$, roughly twice the $A$ rotational constant of $\mathrm{H}_{2} \mathrm{O}$ along its $C_{2}$ axis, suggesting a $\boldsymbol{K}$ rotational temperature of $\sim 50 \mathrm{~K}$. Such free internal rotations clearly would play a significant role in band broadening when the cluster temperature is not sufficiently low. In this experiment, with the use of buffer gas, the rotational and vibrational temperatures are both thermalized to the bath temperature owing to the collisions. In a $77 \mathrm{~K}$ bath for example, the vibrational temperature of the cluster ions produced from the supersonic expansion is effectively lowered from $\sim 200$ to $77 \mathrm{~K}$, but unfortunately, their rotational temperature is raised from $\sim 50$ to $77 \mathrm{~K}$. In this aspect, it thus comes of little surprise that the bandwidths of these $\mathrm{OH}$ stretch transitions could be broadened to more than $10 \mathrm{~cm}^{-1}$ due to coupling of the high-frequency vibrations with the thermally excited internal rotations, as observed experimentally.

\section{Conclusions}

We have shown that collisional cooling of protonated water clusters $\left[\mathrm{H}^{+}\left(\mathrm{H}_{2} \mathrm{O}\right)_{n}\right]$ and deprotonated water clusters $\left[\mathrm{OH}^{-}\left(\mathrm{H}_{2} \mathrm{O}\right)_{m}\right]$ can be achieved with chemically inert buffer gas (either He or $\mathrm{H}_{2}$ ) in a temperature-variable 22-pole ion trap. Using this device has enabled us to conduct infrared spectroscopy as well as dehydration energy measurements under well defined conditions in the temperature range between 77 and $350 \mathrm{~K}$ for both positively and negatively charged cluster ions. In this work, we have determined the first dehydration energies of the water cluster ions from the dissociation activation energies measured in experiments and the internal energies provided by theoretical calculations. The results are in good agreement with literature values. For $\mathrm{H}^{+}\left(\mathrm{H}_{2} \mathrm{O}\right)_{n}$, the cluster bond energy is determined to decrease smoothly from $\sim 17 \mathrm{kcal} \mathrm{mol}^{-1}$ of $n=4$ to $\sim 9$ $\mathrm{kcal} \mathrm{mol}^{-1}$ of $n=8$, and no distinct shell effects have been detected for the second solvation shell formation. In the spectroscopic measurements, we obtain vibrational predissociation spectra of $\mathrm{H}^{+}\left(\mathrm{H}_{2} \mathrm{O}\right)_{6}$ in the free-OH stretch region at an equilibrium cluster temperature of $77 \mathrm{~K}$. Significant reduction in the absorption bandwidths (up to a factor of 2) is observed when cooling the cluster ion from 200 to $77 \mathrm{~K}$. It corroborates the suggestion that the combination of a temperature-variable 22-pole ion trap with infrared lasers is a promising approach for the study of structural transformation (induced either by laser excitation or by temperature change) of cluster ions.

The present work, together with previous experiments conducted for laser-induced reactions of molecular ions ${ }^{42}$ in the Chemnitz group, demonstrates the versatility and utility of this unique trapping device. Future work of this collaboration includes in situ growth and fragmentation ${ }^{43}$ as well as collisioninduced isomerization and deuteration ${ }^{44}$ of water cluster ions in the temperature-variable ion trap in a precisely controlled manner.

Acknowledgment. The authors thank the Academia Sinica and the National Science Council of Taiwan (Grant No. NSC 90-2113-M-001-043) for supporting this research. The financial supports from the NSC-DAAD joint research collaboration program and the Deutsche Forschungsgemeinschaft (DFG) via Forschergruppe FOR 388 "Laboratory Astrophysics" are also gratefully acknowledged.

\section{References and Notes}

(1) Gerlich, D.; Horning, S. Chem. Rev. 1992, 92, 1509.

(2) Duncan, M. A. Int. J. Mass Spectrom. 2000, 200, 545.

(3) See, for example: Searcy, J. Q.; Fenn, J. B. J. Chem. Phys. 1974, 61,5282 .

(4) See, for example: Robertson, W. H.; Kelley, J. A.; Johnson, M. A. Rev. Sci. Instrum. 2000, 71, 4432.

(5) See, for example: Li, G.-Z.; Guan, S.; Marshall, A. G. J. Am. Soc. Mass Spectrom. 1997, 8, 793.

(6) See, for example: Schiffer, J. P.; Drewsen, M.; Hangst, J. S.; Hornekær, L. Proc. Natl. Acad. Sci. U.S.A. 2000, 97, 10697.

(7) Gerlich, D. Adv. Chem. Phys. 1992, 82, 1.

(8) Gerlich, D. J. Chem. Soc., Faraday Soc. 1993, 89, 2199.

(9) Gerlich, D. Phys. Scripta 1995, T59, 256.

(10) Paul, W.; Lücke, B.; Schlemmer, S.; Gerlich, D. Int. J. Mass Spectrom. Ion Processes 1995, 150, 373. Paul, W.; Schlemmer, S.; Lücke, B.; Gerlich, D. Chem. Phys. 1996, 209, 265.

(11) Duley, W. W. Astrophys. J. 1996, 471, L57.

(12) Wayne, R. P. Chemistry of Atmospheres; Oxford University Press: Oxford, U.K., 1991.

(13) Fredericks, S. Y.; Jordan, K. D. Mol. Phys. 1997, 92, 445.

(14) Hunter, E. P. L.; Lias, S. G. J. Phys. Chem. Ref. Data 1998, 27, 413. 
(15) Cunningham, A. J.; Payzant, J. D.; Kebarle, P. J. Am. Chem. Soc. 1972, 94, 7627. Lau, Y. K.; Ikuta, S.; Kebarle, P. J. Am. Chem. Soc. 1982, 104, 1462.

(16) Yeh, L. I.-C.; Okumura, M.; Myers, J. D.; Price, J. M.; Lee, Y. T. J. Chem. Phys. 1989, 91, 7319.

(17) Crofton, M. W.; Price, J. M.; Lee, Y. T. In Clusters of Atoms and Molecules; Haberland, H., Ed.; Springer-Verlag: Berlin, 1994; Vol. II, p 44. Price, J. M. Ph.D. Thesis, University of California at Berkeley, 1990. (18) Jiang, J. C.; Wang, Y.-S.; Chang, H.-C.; Lin, S. H.; Lee, Y. T.; Niedner-Schatteburg, G.; Chang, H.-C. J. Am. Chem. Soc. 2000, 122, 1398.

(19) Meot-Ner, M.; Speller, C. V. J. Phys. Chem. 1986, 90, 6616

(20) Magnera, T. F.; David, D. E.; Michl, J. Chem. Phys. Lett. 1991, $182,363$.

(21) Shi, Z.; Ford, J. V.; Wei, S.; Castleman, A. W. J. Chem. Phys. 1993, 99, 8009 .

(22) Schindler, T.; Berg, Ch.; Niedner-Schatteburg, G.; Bondebey, V. E. Chem. Phys. Lett. 1996, 250, 301

(23) Chaudhuri, C.; Wang, Y.-S.; Jiang, J. C.; Lee, Y. T.; Chang, H.C.; Niedner-Schatteburg, G. Mol. Phys. 2001, 99, 1161.

(24) Tuckerman, M.; Lassonen, K.; Sprik, M.; Parrinello, M. J. Phys. Chem. 1995, 99, 5749. Tuckerman, M.; Lassonen, K.; Sprik, M.; Parrinello, M. J. Chem. Phys. 1995, 103, 150.

(25) Wales, D. J. J. Chem. Phys. 1999, 110, 10403. Wales, D. J. J. Chem. Phys. 1999, 111, 8429 . 710 .

(26) Singer, S. J.; McDonald, S.; Ojamäe, L. J. Chem. Phys. 2000, 112,

(27) Xantheas, S. S. J. Am. Chem. Soc. 1995, 117, 10373.

(28) Novoa, J. J.; Mota, F.; del Valle, C. P.; Planas, M. J. Phys. Chem. A 1997, 101, 7842.

(29) Lovejoy, E. R.; Bianco, R. J. Phys. Chem. A 2000, 104, 10280.

(30) Zemansky, M. W. Heat and Thermodynamics, 5th ed.; McGrawHill: New York, 1968; p 438.

(31) Jones, R. M.; Gerlich, D.; Anderson, S. L. Rev. Sci. Instrum. 1997, $68,3357$.

(32) Frisch, M. J.; Trucks, G. W.; Schlegel, H. B.; Scuseria, G. E.; Robb,

M. A.; Cheeseman, J. R.; Zakrzewski, V. G.; Montgomery, J. A., Jr.;

Stratmann, R. E.; Burant, J. C.; Dapprich, S.; Millam, J. M.; Daniels, A.
D.; Kudin, K. N.; Strain, M. C.; Farkas, O.; Tomasi, J.; Barone, V.; Cossi, M.; Cammi, R.; Mennucci, B.; Pomelli, C.; Adamo, C.; Clifford, S.; Ochterski, J.; Petersson, G. A.; Ayala, P. Y.; Cui, Q.; Morokuma, K.; Malick, D. K.; Rabuck, A. D.; Raghavachari, K.; Foresman, J. B.; Cioslowski, J.; Ortiz, J. V.; Stefanov, B. B.; Liu, G.; Liashenko, A.; Piskorz, P.; Komaromi, I.; Gomperts, R.; Martin, R. L.; Fox, D. J.; Keith, T.; Al-Laham, M. A.; Peng, C. Y.; Nanayakkara, A.; Gonzalez, C.; Challacombe, M.; Gill, P. M. W.; Johnson, B. G.; Chen, W.; Wong, M. W.; Andres, J. L.; Head-Gordon, M.; Replogle, E. S.; Pople, J. A. Gaussian 98, revision A.5; Gaussian, Inc.: Pittsburgh, PA, 1998.

(33) Wang, Y.-S.; Jiang, J. C.; Cheng, C.-L.; Lin, S. H.; Lee, Y. T.; Chang, H.-C. J. Chem. Phys. 1997, 107, 9695. Chang, H.-C.; Wang, Y.-S.; Lee, Y. T.; Chang, H.-C. Int. J. Mass Spectrom. 1998, 179/180, 91.

(34) Troe, J. J. Chem. Phys. 1977, 66, 4745. Troe, J. J. Chem. Phys. 1977, 66, 4758

(35) Lide, D. R. CRC Handbook of Chemistry and Physics, 76th ed.; CRC Press: Boca Raton, FL, 1995; pp 6-10.

(36) Keesee, R. G.; Castleman, A. W. J. Phys. Chem. Ref. Data 1986, 15,1016 .

(37) Ochterski, J. W. download of whitepaper from www.Gaussian.com 2000 .

(38) Klots, C. E. J. Chem. Phys. 1985, 83, 5854. Klots, C. E. Z. Phys. D 1991, 20, 105 .

(39) Dunbar, R. C. J. Phys. Chem. 1994, 98, 8705.

(40) Price, J. M.; Crofton, M. W.; Lee, Y. T. J. Chem. Phys. 1989, 91, 2749. Price, J. M.; Crofton, M. W.; Lee, Y. T. J. Phys. Chem. 1991, 95, 2182 .

(41) Wang, Y.-S.; Chang, H.-C.; Jiang, J. C.; Lin, S. H.; Lee, Y. T.; Chang, H.-C. J. Am. Chem. Soc. 1998, 120, 8777.

(42) Schlemmer, S.; Kuhn, T.; Lescop, E.; Gerlich, D. Int. J. Mass Spectrom. 1999, 187, 589. Schlemmer, S.; Lescop, E.; von Richthofen, J.; Gerlich, D.; Smith, M. A. J. Chem. Phys. 2002, 117, 2068

(43) Schlemmer, S.; Luca, A.; Glosik, J.; Gerlich, D. J. Chem. Phys. 2002, 116, 4508 .

(44) Yamaguchi, S.; Kudoh, S.; Okada, Y.; Orii, T.; Takeuchi, K. Chem Phys. Lett. 2002, 359, 480. 